\title{
Cardioprotective Effects of Amlodipine on Ischemia and Reperfusion in Two Experimental Models
}

\author{
Paul T. Hoff, BA, Yasuo Tamura, MD, and Benedict R. Lucchesi, MD, PhD
}

The cardioprotective effect of amlodipine, a long. acting dithydropyridine derivative, was studied in 2 experimental models of ischemia and reperfusion.

Isolated and blood-perfused feline hearts were made globally ischemic for 60 minutes and then repertused for 60 mimules. Alterations of left ventricular developed pressure and compliance were monitored in both amlodipine-treated hearts and salinetreated control animals. Changes in perfusion pressure indicated that amlodipine significantly reduced myocardial oxysen consumption and coronary vascular resistance. Furthermore, a progressive increase in resting left ventricular dlastolic pressure indicated that amiodipine, administered before the onset of global ischemia, attenuated the development of ischemic contracture. Return of contractlle function $\mathbf{6 0}$ minutes after reperfusion and maintenance of tissue concentrations of electrolytes were significantly better in the amlodipinetreated group than in the control animals.

In Intact canine hearts, regional myocardlal ischemia was induced for $\mathbf{9 0}$ minutes, followed by 6 hours of reperfusion. Alhough the hemodynamic variables and the size of the region of risk did not differ significantly between treated animais and control animals, the infarct size was significantly smaller in the amlodipine-treated group than in the control animals, and a gradual reduction in coronary blood flow was observed in the control group that was prevented in the amlodipine group. A comparison of these findings with those observed with oxygen radical scavengers also is discussed.

A detalled report of these studies was published in The American Journal of Cardiology (1989;64:1011-1161). This revlew is included here to maintain continuity of the symposium for the convenience of the reader.

(Am J Cardiol 1990;66:10H-16H)

From the Department of Pharmacology, The University of Michigan Medical School, Amn Arbor, Michigan. This study was supported by grant HL-19782-10 from the Heart, Lung, and Blood Institute, National Institutes of Health, Bethesda, Maryland; and a grant from Pfizer Central Research, Sandwich, Kent, United Kingdom.

Address for reprints: Benedict R. Lucchesi, PhD, Department of Pharmacology, M6322 Medical Science Building I, The University of Michigan Medical School, Ann Arbor, Michigan 48109-0626.
$\Delta$ mlodipine is a dihydropyridine calcium antagonist shown to have a gradual onset and a sustained duration of action. ${ }^{1.3}$ Because of the selectivity of the dihydropyridines for vascular smooth muscle and their lack of significant cardiac side effects, ${ }^{4,5}$ they may have the potential to limit myocardial injury during ischemia and reperfusion. ${ }^{6} 8$

Myocardial ischemia is associated with impaired calcium homeostasis. ${ }^{9-11}$ Ischemic tissue injury causes an increase ${ }^{12 \cdots 14}$ in free intracellular calcium that leads to diminished recovery of myocardial contractile function, compromised membrane integrity and decreasing reserves of cellular adenosine triphosphate. Inasmuch as the short-acting calcium antagonists diltiazem and nifedipine have been shown to protect the myocardium from irreversible tissue injury after global or regional ischemia followed by reperfusion, ${ }^{15-17}$ we assessed the potential for additional cardioprotective effects of a calcium antagonist with a prolonged duration of action, amlodipine, in 2 experimental models. The isolated and blood-perfused feline heart provided an experimental model for the induction of global myocardial ischemia ${ }^{18}$ and was used to ascertain the effects of amlodipine on mechanical and biochemical function after global ischemia and reperfusion. The intact canine heart provided a model for regional myocardial ischemia followed by reperfusion. ${ }^{19,20}$ In this review, we summarize our previously reported experimental work with these 2 models, ${ }^{21}$ followed by a discussion of the potential usefulness of amlodipine and its mechanisms of action in myocardial ischemia and reperfusion syndromes. We also compared these findings with those observed with oxygen radical scavenging agents.

\section{EXPERIMENTS IN ISOLATED AND BLOOD- PERFUSED FELINE hEARTS}

In an experimental model of isolated and blood-perfused feline hearts made globally ischemic for 60 minutes and followed by reperfusion for 60 minutes, infusion of amlodipine before the induction of global ischemia significantly $(p<0.05)$ curtailed the development of ischemic contracture. There was minimal or no increase in left ventricular end-diastolic pressure in the amlodipinetreated hearts, compared with a significant progressive increase in left ventricular end-diastolic pressure in saline-treated control animals.

Although no ventricular fibrillation occurred during the ischemic period, all hearts fibrillated immediately when reperfused. A better spontaneous recovery of sinoatrial rhythm $(85.7 \%)$ was observed in the amlodipine- 
treated hearts than in the saline-treated hearts $(54.5 \%)$, but the difference was not statistically significant.

Significant $(p<0.05)$ decreases in left ventricular compliance were observed in the isolated hearts of both groups. However, the shift to the left in pressure-volume curves of the amlodipine-treated group was significantly $(p<0.05)$ less than that in the placebo group.

Pretreatment with amlodipine attenuated the declines in left ventricular developed pressure (Fig. 1) and left ventricular $+\mathrm{dP} / \mathrm{dt}$ (Fig. 2) observed in all hearts after ischemia and reperfusion. Thus, amlodipine protected the reperfused ischemic heart from depression of myocardial contractility. Coronary blood flow increased $30 \%(\mathrm{p}=$ $0.021)$ in the saline-treated hearts and $127 \%(p=0.002)$ in the amlodipine-treated hearts (Fig. 3). Despite the obviously greater increase in the amlodipine group, the differences between treatments were short of statistical significance.

Amlodipine significantly reduced the loss of intracellular potassium and the accumulation of calcium during reperfusion (Fig. 4). These results support the conclusion that this agent preserves both systolic and diastolic functions of the isolated ischemic and reperfused heart.

\section{EXPERIMENTS IN INTACT CANINE HEARTS}

Is amlodipine capable of actually reducing anatomic myocardial infarct size? To answer this question, anesthetized dogs were subjected to 90 minutes of coronary artery occlusion followed by 6 hours of repcrfusion through a critical stenosis. The dogs were assigned randomly to treatment with either amlodipine $(150 \mu \mathrm{g} / \mathrm{kg}$ dissolved in $20 \mathrm{ml}$ saline) or with saline alone. Treatment was administered 75 minutes after the start of regional

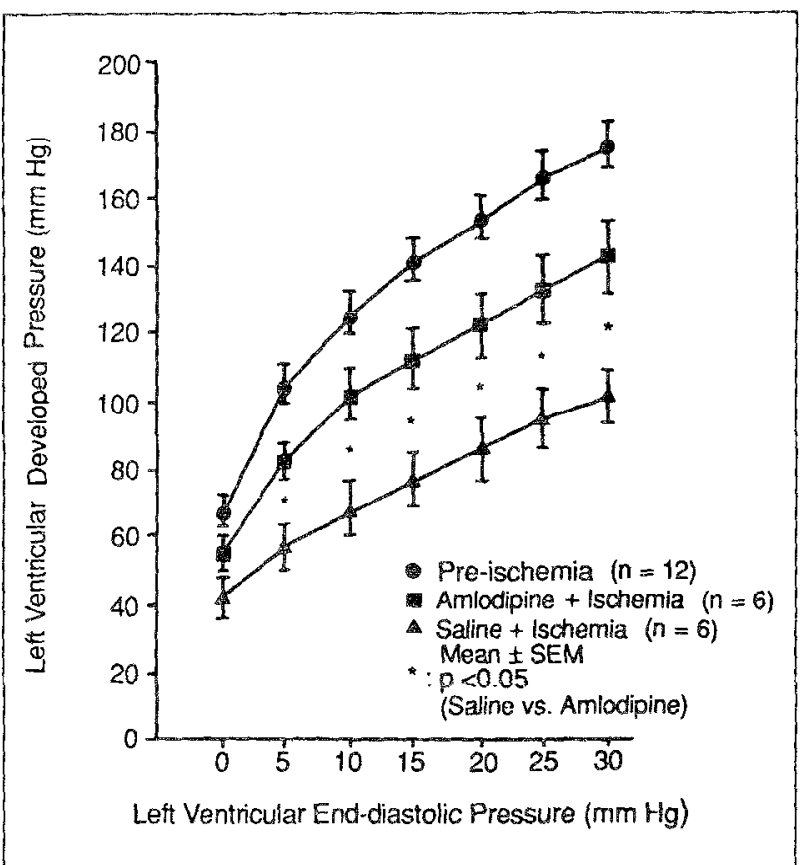

FIGURE I. Ventricular function curves of the isolated and blood-pertused feline heart. SEM = standard error of the mean. (Redrawn, with permission, from Hoff et al. ${ }^{21}$ ) myocardial ischemia and 15 minutes before the onset of reperfusion.

The overall area at risk (measured by the Evans-blue dye technique) for both amlodipine-treated and control dogs was $40.2 \pm 4.9 \%$. Amlodipine achieved a $24.8 \%$ reduction ( $\mathrm{p} \leq 0.025)$ in ultimate infarct size (measured by the triphenyltetrazolium chloride technique), determined as a percentage of the area at risk (Fig. 5). A significant difference $(p<0.05)$ was also observed when the infarct size was expressed as a percent of the left ventricle: $18.6 \pm 1.5 \%$ for the saline group and $13.6 \pm$ $1.6 \%$ for the amlodipine group. There were no significant differences in hemodynamics between the 2 groups.

The calcium concentration of tissue within the area of risk was greater than that of myocardial tissue from the nonischemic region (Fig. 6). Amlodipine significantly decreased the elevation of calcium in the noninfarcted tissue within the area at risk and somewhat diminished calcium in the center of the infarcted zone.

\section{DISCUSSION}

These experiments in isolated and blood-perfused feline hearts show that amlodipine given before the onset of global ischemia preserves myocardial function. Similar cardioprotection has been demonstrated with other calcium antagonists. ${ }^{22-24}$ In addition, we demonstrated in the intact canine heart that amlodipine given after the onset of ischemia 15 minutes before reperfusion reduces the extent of myocardial necrosis after 90 minutes of regional ischemia. Calcium antagonists, ${ }^{6,15,17}$ administered before the onset of ischemia, have been shown to reduce infarct size in models of permanent occlusion and ischemia-reperfusion.

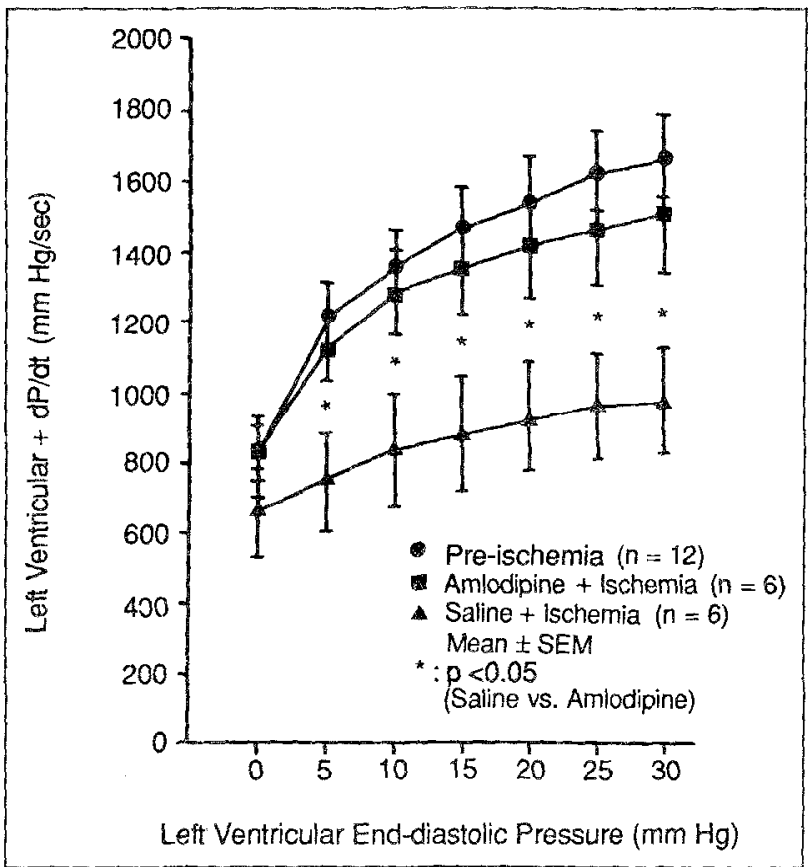

FIGURE 2. Left ventricular $+d P / d t$ of the cat blood-perfused, isolated heart. SEM = standard error of the mean. (Redirawn, with permission, from Hoff et al. ${ }^{21}$ ) 
The isolated and blood-perfused feline heart allowed an assessment of the effects of amlodipine on myocardial performance and electrolyte balance independent of hemodynamic and central nervous system variations. In addition, this model had the advantage of assuring global ischemia and eliminating the possible mechanism of coronary steal. ${ }^{25}$

Experiments in isolated myocytes have shown that pretreatment with the calcium antagonists nifedipine and diltiazem did not prevent hypercontracture, but pretreatment with the nonspecific agents lidoflazine and flunarazine did afford protection. ${ }^{26}$ These findings suggest a possible intracellular action of calcium regulation. Spere-

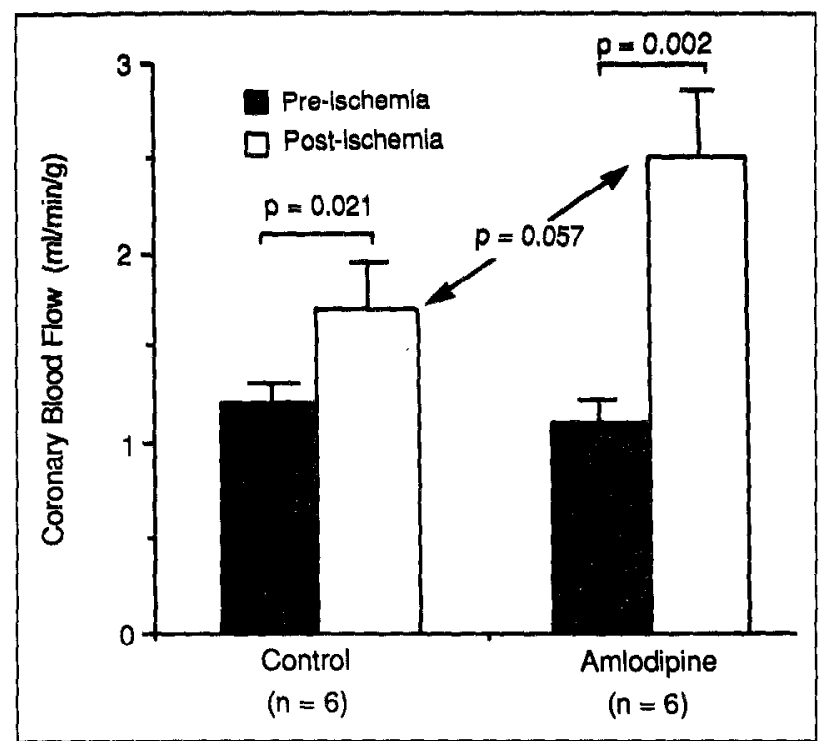

FIGURE 3. Coronary blood flow before and after 60 minutes of ischemia plus reperfusion. (Redrawn, with permission, from Hoff et al, 21) lakis ${ }^{27}$ suggested that the increase in calcium $m_{i}$ during ischemia might be a consequence of failure of the metabolic processes to extract free calcium from the cell. Dhalla et a ${ }^{28}$ demonstrated an inhibition of sarcoplasmic reticular calcium adenosine triphosphatase uptake and sodium-calcium exchange mechanisms during anoxia and ischemia. It is likely that calcium has more than 1 route of entry during reperfusion. The dihydropyridines are believed to bind selectively to sites directly within the ion channel, ${ }^{29}$ which may impart some undetermined action independent of ion flux. ${ }^{30}$ This action may provide an explanation for the observation that specific calcium antagonists can postpone, but not abolish, the reperfusioninduced accumulation of calcium that leads to cell death.

Our data from the isolated cardiac preparation suggest that amlodipine limits the alterations in electrolyte homeostasis, namely, the increases in total tissue calcium and sodium and the decrease in potassium associated with ischemia and reperfusion. The increase we observed in tissue calcium is compatible with the rapid accumulation of calcium associated with reperfusion. This cannot occur solely through activation of the slow channels. ${ }^{31}$ Various mechanisms have been proposed for the gradual deterioration of the membrane during ischemia. These include activation of phospholipases ${ }^{32}$ or accumulation of lipids ${ }^{33}$ or oxygen free radicals, ${ }^{34}$ which remove the physical barriers allowing the free diffusion of calcium down its concentration gradient at reperfusion. The decline in total calcium after pretreatment with amlodipine may result from an inhibition of the events that trigger membrane damage during ischemia; the metabolic and structural changes that normally provide the substrate for reperfusion injury (calcium overload) may be eliminated.

Amlodipine inhibited the increase in left ventricular end-diastolic pressure throughout the 60 minutes of ischemia. By suppressing the induction of myocyte hypercon-

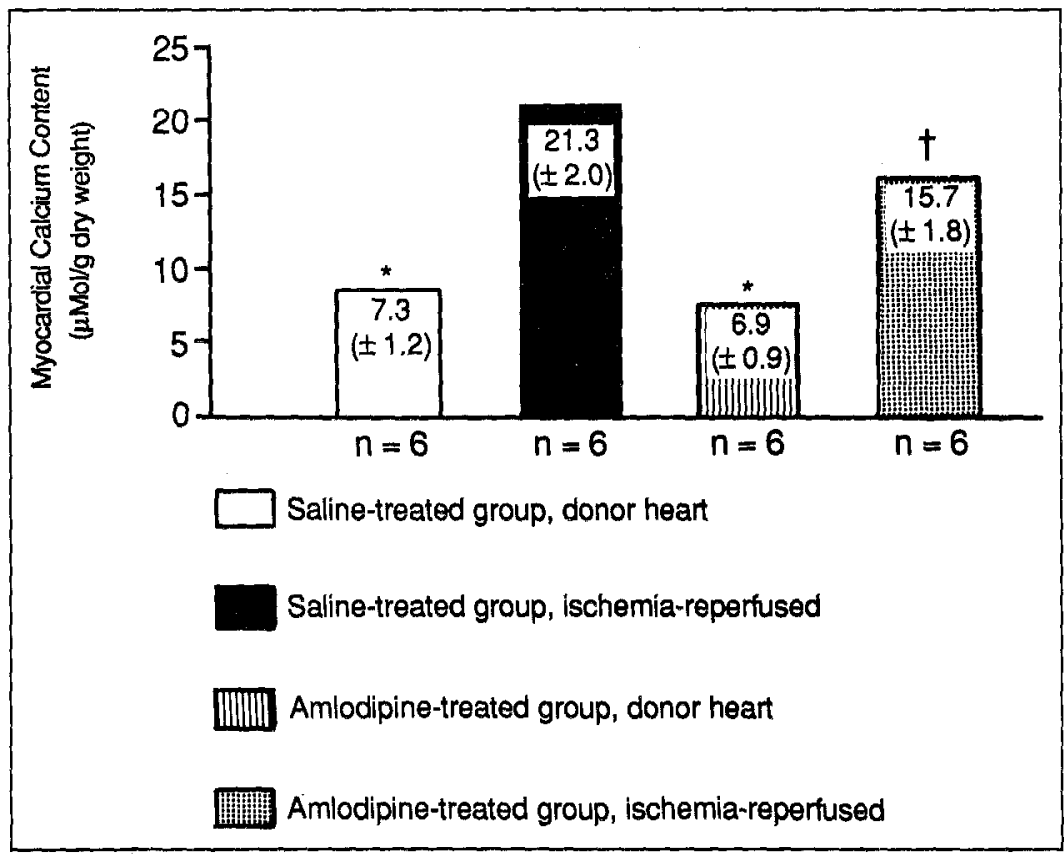

FIGURE 4. Myocardial calcium content (umol/g, dry welght) * $p \leq 0.05$ : donor heart vs ischemia-reperfused heart. tp క0.05: saline-treated group vs amlodipine-treated group. (Data from Hoff et al. 21) 
tracture, amlodipine may obviate additional mechanical disruption and chemical degradation of the sarcolemmal membrane and render the cells less susceptible to calcium overload during reperfusion.

The intact canine heart model provided the opportunity to assess ơrug responses under more physiologic conditions. The ability of amlodipine to reduce the extent of myocardial necrosis that occurs during the late stage of ischemia and reperfusion was assessed in this model. We previously demonstrated that reproducible rcgional myocardial necrosis can be induced in the canine heart after temporary coronary occlusion followed by reperfusion. ${ }^{15,19,20}$ With physiologic hemodynamic and central nervous system responses maintained, it was possible to monitor drug-related changes in systemic arterial blood pressure, heart rate, coronary blood flow and myocardial oxygen consumption.

First-generation calcium antagonists administered before the onset of coronary occlusion in intact animal hearts have been shown to reduce infarct size and im- prove cardiac function. ${ }^{15,35}$ By directly inhibiting neutrophil activation, these agents may help to reduce the ultimate extent of damage. ${ }^{36,37}$ However, they have not been shown to be effective if administered at the time of perfusion. ${ }^{30}$ Solutions containing low concentrations of calcium or acidic reperfusate cannot prevent cellular damage, although they can delay its onset. 31

Much of the damage associated with reperfusion is thought to occur within minutes of the resumption of flow. ${ }^{38}$ Total cellular calcium concentration remains constant during ischemia and increases precipitously during reperfusion..$^{39}$ The rapid loss of sarcolemmal membrane integrity associated with restoration of flow and derangement of homeostatic mechanisms most likely prevent calcium antagonists from improving cardiac function and reducing infarct size when administered during reperfusion only. Ischemia primes the cells for destruction through activation of proteases, oxygen free radicals and calcium adenosine triphosphatase. ${ }^{11,28}$ During reperfusion, the sarcolemma is disrupted, a phenomenon that is
FIGURE 5. Region of tissue representing the area at risk as a percentage of the left ventricle and myocardial infarct size taken as a fraction of the area at risk. NS = not significant. (Redrawn, with permission, trom Hoff et al.21)
FIGURE 6. Tissue eakium $\left(\mathrm{Ca}^{2+}\right)$ concentration in the canine myocardium after $\mathbf{9 0}$ minutes of occlusion and 6 hours of reperfusion. NS = not significant; SEM = stan" dard error of the mean. (Redrawn, with permission, from Moft et all.21)
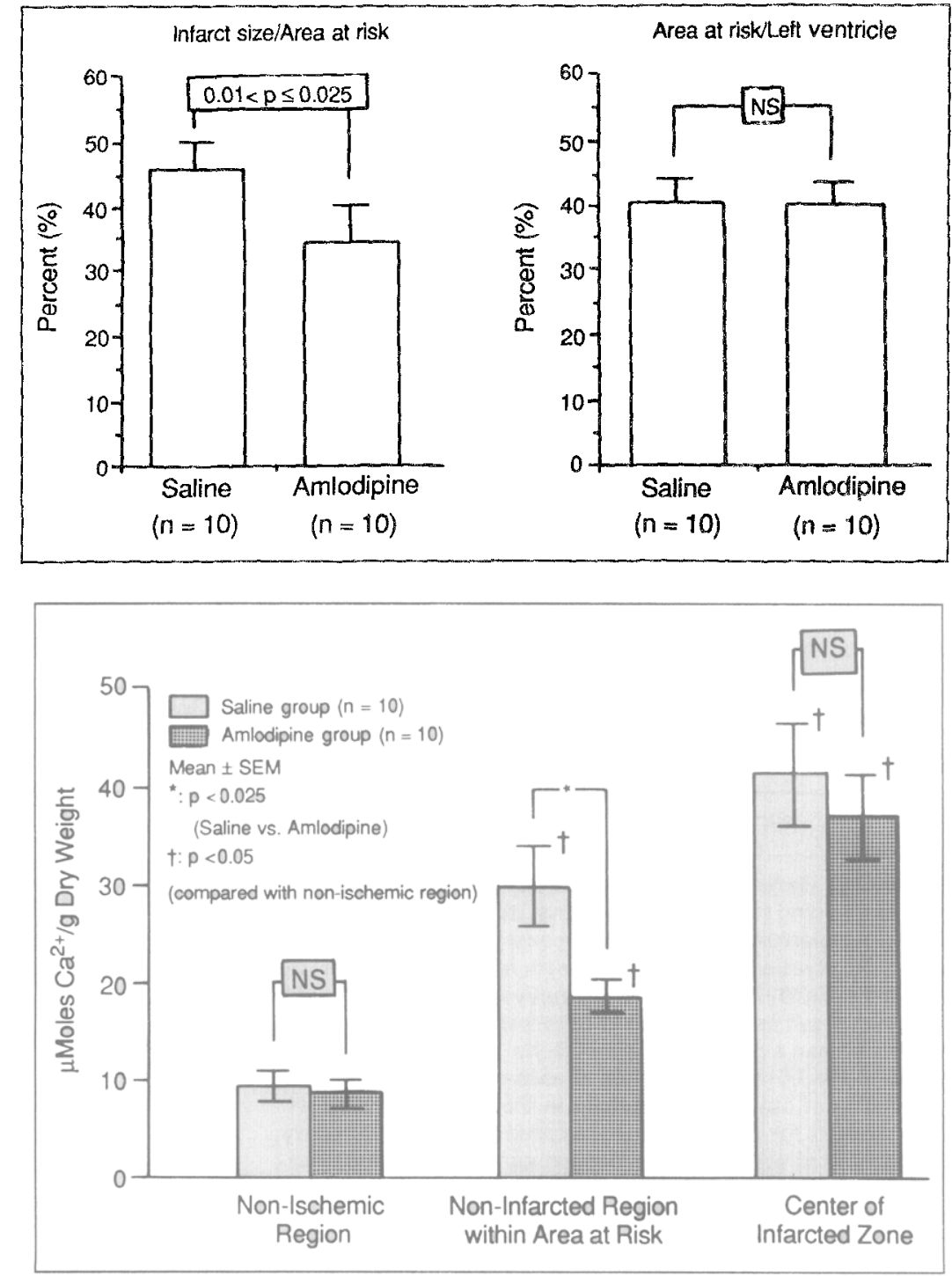
not manifest during ischemia alone, although the cell membrane has altered permeability. ${ }^{31,40,41}$ Hence, calcium can move freely into the cytoplasmic space during reperfusion. Calcium influx may be one of the final common pathways leading to myocardial dysfunction and necrosis.

Amlodipine administered 15 minutes before the beginning of reperfusion reduced infarct size and intracellular calcium concentrations in the noninfarcted tissue in the region at risk. Neither verapamil nor diltiazem administered at the time of reperfusion exhibited a cardioprotective effect, although nifedipine and the calmodulin antagonist, $W-7$, were effective when administered at reperfusion or before ischemia. ${ }^{30}$ Thus, calcium antago. nists may have different effects on the sarcolemmal mem. brane, with the second-generation calcium antagonist, amlodipine, showing a greater ability to prevent sarcolemmal disruption on reperfusion. Additionally, nifedipine may provide an intracellular action similar to that of W-7 on calmodulin. 42

The results of our experiments suggest that the reduction in myocardial infarct size was independent of altered hemodynamics, which did not show differences between treated and control dogs. These results agree with our findings in the isolated hearts and suggest that amlodipine's mechanism of action is not due simply to altering heart rate or blood pressure.

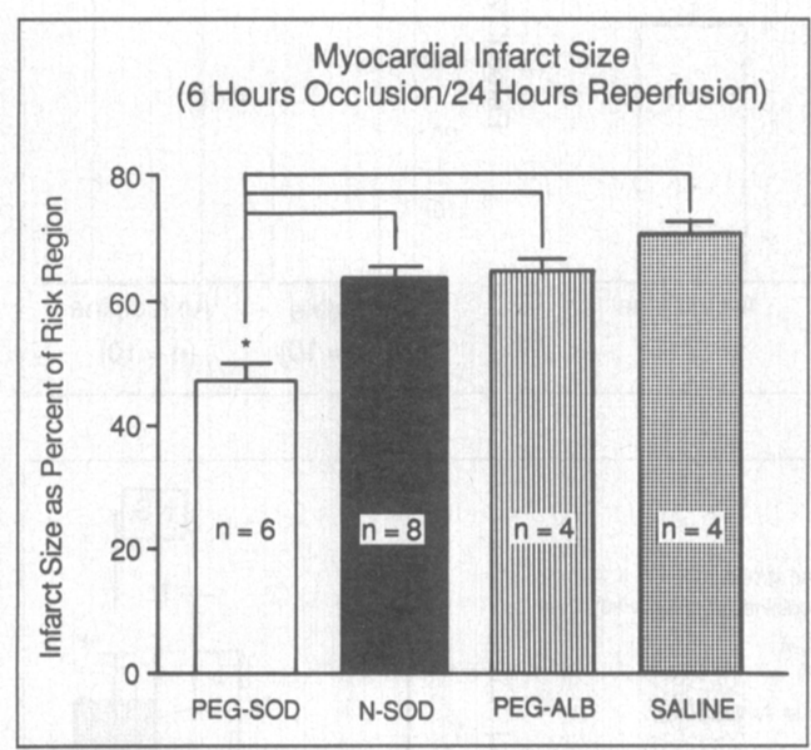

FICURE 7. Reduction in myocardial infarct size in the canine heart subjected to 6 hours of regional lschemia followed by 24 hours of reperfusion. Salvage of myocardial tissue is achleved with the polyethylene conjugated form of superoxide dismutase (PEG-SOD) in contrast to the native enzyme (SOD), which does not result in a reduction in irreversible myocardial Injury. PEG-SOD has a pharmacologic half-llfe $>30$ hours as compared to the 10-minute half-llfe of native SOD. The continued generation of oxygen free radicals in the postischemic heart may account for the progressive extenslon of myocyte injury. An agent that will provide protection against the damage associated with reperfusion must possess a pharmacokinetic profile that will extend into the period during which irreversible cell injury can occur. PEG-ALB = polyethylene conjugated form of albumin.
Excessive influx of calcium occurs almost exclusively during reperfusion and cannot be due entirely to in. creased conductance through the calcium channel. ${ }^{31,43}$ The administration of amlodipine 15 minutes before reperfusion achieved a reduction of infarct size typical of hearts treated before ischemia, but distinct from those treated only during reperfusion. Amlodipine administered prophylactically during late ischemia may provide enough protection to sustain the sarcolemma and calcium homeostasis mechanisms during reperfusion. Lowered accumulation of tissue calcium compared with control animals indicates that amlodipine may directly protect the myocardium during ischemia, and the effect may persist into the reperfusion phase either through membrane stabilization or intracellular mechanisms. Moreover, amlodipine may inhibit activation of leukocytes that would curtail enzymatic and oxidative damage consequent to ischemia and reperfusion. ${ }^{36,37}$

The evidence for generation of oxygen free radicals during myocardial reperfusion would suggest that superoxide dismutase (SOD) and other free radical scavengers might alter the extent of myocardial injury. A number of studies from our laboratory as well as those of others have supported the hypothesis that free radical scavengers have a protective action against the extension of myocardial injury related to reperfusion. ${ }^{44} \mathrm{Chi}$ et $a{ }^{45}$ have presented evidence for the sustained presence of oxygen radical scavenger activity as being essential for the prevention of infarct extension rather than delay of necrosis after reperfusion. Figure 7 presents a summary of the results of a comparison made between the native form of SOD (with a half-life of 10 minutes) and the polyethylene conjugated form of the enzyme (PEG-SOD), which has a half-life in excess of 30 hours. Only the PEG-SOD was effective in reducing ultimate infarct size when assessed 24 hours after reperfusion. The interpretation of the results conforms to that cited earlier ${ }^{46}$ in which there was a direct demonstration of sustained oxyradical generation in the postischemic heart. Additional studies are needed to determine whether there is a link between the reduction in infarct size as achieved with calcium antagonists and that obtained with oxygen radical scavengers. Do oxyradicals impair the removal of calcium from the myocardial cell? Do calcium antagonists provide their beneficial effect by interfering with ion movement in the slow calcium channel? Do calcium antagonists affect cell-tocell interactions that are known to participate in reperfusion injury such as the events involving neutrophil-mediated cell injury? Substantial investigative efforts must now be directed toward resolving some of the questions regarding the manner in which several diverse pharmacologic agents can achieve a similar outcome with respect to reducing myocardial reperfusion injury.

The pharmacokinetic profile of amlodipine may prove valuable in protection of the postischemic heart. A single intravenous dose of $10 \mathrm{mg}$ resulted in an absolute bioavailability of $64 \%$ and a calculated half-life of 34 hours. Similar values were obtained after oral administration of the drug. The pharmacokinetic data with amlodipine contrast with the results of similar studies using most 
other dihydropyridine and nondihydropyridine calcium antagonists. Most dihydropyridine calcium antagonists have an elimination half-life of about 3 to 10 hours. The nondihydropyridine calcium antagonists show an elimination half-life of 3 to 6 hours. The prolonged generation of oxyradicals in the postischemic heart may adversely affect calcium homeostasis. It is intriguing to suspect, therefore, that amlodipine may serve to modulate the otherwise unfavorable change in intracellular calcium and thereby reduce the extent of irreversible cell injury associated with reperfusion. The prolonged pharmacologm ic action of amlodipine would provide the extended duration of protection necessary to reduce the extent of the cellular damage in the postischemic heart.

There is a growing body of evidence indicating the participation of reactive oxygen metabolites (superoxide anion, hydrogen peroxide, hydroxyl anion) as contributors to the tissue damage associated with reperfusion. 44,47 The exact mechanism by which reactive oxygen species produce alterations in cardiac function and myocyte viability is not known. Recent studies have suggested that the sarcolemmal membrane is altered by exposure to superoxide anion, and this may result in depressing the calcium-pump mechanism that facilitates efflux of the divalent ion from the myocardial cell. ${ }^{48,49}$ The inhibition of sarcolemmal calcium-pump activities by superoxide anion was decreased by the addition of dithiothreitol or cysteine in a dose-dependent manner. ${ }^{49}$ Heart sarcolemmal sulfhydryl groups were depressed by superoxide anion, hydrogen peroxide and hydroxyl anion. SOD, catalase and D-mannitol showed protective effects on the sulfhydryl group depression by the several reactive oxygen metabolites. The increase in intracellular calcium observed to occur in myocardial ischemia/reperfusion injury may be a manifestation of an oxygen free radicalmediated depression of the mechanism(s) responsible for removal of cytosolic free calcium. Spin trapping techniques have been used to demonstrate the formation of free radicals during regional myocardial ischemia. Evidence has been provided to indicate the presence of oxygen- and carbon-centered radical adducts in the coronary venous blood draining from the ischemic bed on reperfusion of the ischemic heart. ${ }^{50}$ Studies in the canine heart subjected to 90 minutes of regional ischemia followed by reperfusion have demonstrated the sustained generation of oxyradicals 1 to 3 hours after the restoration of blood flow. There was an associated progressive increase in infarct size supporting the view that a chain reaction of oxyradicals contributes to the propagation of myocardial cell damage in the postischemic heart. ${ }^{46}$

In conclusion, experimental data demonstrate that amlodipine, a second-generation long-acting dihydropyridine with somewhat unique binding properties, is effective in preserving myocardial contractile function and attenuating calcium accumulation after 60 minutes of ischemia and reperfusion when administered before the onset of ischemia. It also limits ultimate infarct size when administered 15 minutes before the beginning of reperfusion and after 75 minutes of regional ischemia. The protective effect was associated with reduced accumulation of calcium in noninfarcted tissue in the area at risk. Our data suggest that amlodipine may have utility as a cardioprotective agent to preserve cardiac function and cell viability during myocardial ischemia and reperfusion.

Comparable data with respect to the reduction in in farct size and the preservation of contractile function after brief periods of global or regional ischemia have been obtained with agents known to scavenge oxygen free radicals. There is evidence to suggest that oxyradicals may influence the mechanisms that control calcium accumulation in the myocardial cell and thereby lead to irreversible cell injury or an alteration in contractile function. It is intriguing to speculate that a common mechanism that subjects the myocyte to permanent damage may be operative. Amlodipine, with its interesting pharmacologic and pharmacokinetic profiles, may provide a means of modulating the myocardial injury in the postischemic heart.

\section{REFERENCES}

1. Reid JL. Pharnacokinetics of $\mathrm{Ca}^{2+}$ antagonists. I Cardiovasc Pharmacol $1988 ; 12: 522-526$

2. Echizen H1, Vogelsang B, Eichelbaum M. Effects of d,1-verapamil, nifedipine, and diltiazem. Clin Pharmacol Ther 1986;2:425-449.

3. Burges RA, Carter AJ, Gardiner DG, Higgins AJ. Amlodipine, a new dihydropyridine calcium blocker with slow onset and long duration of action (abstr), $B r J$ Pharmacol 1985;85:281P.

4. Singh $\mathrm{BN}$. The mechanism of action of $\mathrm{Ca}^{2+}$ antagonists relative to their application. Br J Clin Pharmacol 1986;21:109-225.

5. Triggle DJ, Swamy VC. Pharmacology of agents that affect calcium: agonists and antagonists. Chest 1980;78:174-179.

6. Henry PD, Schuchlib R, Borda CJ, Roberts R, Williamson JR, Sobel BE. Effects of nifedipine on myocardial perfusion and ischemic injury in dogs. Circ Res 1978:43:372-380.

7. Nayler WG, Ferrari R, Williams A. Protective effect of pretreatment with verapamil, nifedipine, and propranolol on mitochondrial function in the ischemic and reperfused myocardium. Am J Cardiol 1980;46:242-248.

8. Perez PE, Sobel BE, Henry PD. Improved performance of ischemic canine myocardium in response to nifedipine and diltiazem. Am $J$ Physiol 1980;239:H658-H663.

9. Trump BF, Mergner WJ, Kahang MW, Saladino AJ. Studies on the subcellular pathophysiology of ischemia. Circulation 1976;53:I-117-I-126.

10. Katz AM, Reuter H. Cellular calcium and cardiac cell death. An J Cardiol 1979;44:188-190.

11. Buja LM, Hagler HK, Willerson JT. Altered calcium homeostasis in the pathogenesis of myocardial ischemic and hypoxic injury. Cell Calcium 1988;9:205-217.

12. Reimer KA, Jennings RB. Myocardial ischemia, hypoxia, and infarction. In: Fozzard HA, Haber E, Jennings RB, Katz AM, Morgan HE, eds. The Heart and Cardiovascular Systern. New York: Raven Press, 1986:1133-1201.

13. Buja LM. Basic pathological processes of the heart: relationship to cardiomyopathies. In: Sperelakis N, ed. Physiology and Pathophysiology of the Heart. Boston: Martinus Nijhoff, 1984:43-57.

14. Hagler HK, Burton KP, Buja LM. Electron probe x-ray microanalysis of normal and injured myocardium: methods and results. In: Hutchinson TE, Som* lyo AP, eds. Microprobe Analysis of Biological Systems. New York: Academic Press, 1981:122-125.

15. Bush LR, Romson JL, Ash JL, Lucchesi BR. Effects of diltiazem on extent of ultimate myocardial injury resulting from temporary coronary artery occlusion in dogs. J Cardiovasc Pharmacol 1982;4:285-296.

16. Tumas J, Deth R, Kloner RA. Effects of nisoldipine, a new calcium antagonist, on myocardial infaret size and cardiac dynamics following acute myocardial infarction. $J$ Cardiovase Pharmacol 1985;7;361-367.

17. Selwyn AP, Wolman E, Fox K, Horlock P, Pratt T, Klein M. The effects of nifedipine on acute experimental myocardial ischemia and infaretion in dogs. Circ $\operatorname{Res} 1979 ; 4$ it: 16-23.

19. Vogel WM, Lucchesi BR. An isolated blood perfused feline heart preparation for evaluating pharmacological interventions during myocardial ischemia. $J$ Pharmacol Methods 1980:4:291-303.

19. Jolly SR, Kane WJ, Bailie MB, Abrans GD, Lucchesi BR. Canine myocardin al reperfusion injury: its reduction by the combined administration of superoxide dismutase and catalase. Circ Res 1984;54:27\%-285.

20. Werns SW, Shea MJ, Mitsos SE, Dysko RC, Fantone JC, Schork A, Abrams 
GD, Pitt B, Lucchesi BR. Reduction of the size of infarction by allopurinol in the ischemic reperfused canine heart. Circulation 1986;73:518-524.

21. Hoff PT, Tamura $Y$, Lucchesi $B R$. Cardioprotective effects of amlodipine in the ischemic-reperfused heart. Am J Cardiol 1989;64:1011-116I.

22. Bush LR, Li Y-P, Shalfer M, Jolly SR, Lucchesi BR. Protective effects of diltiazem during myocardial ischemia in isolated cat hearts. J Pharmacol Exp Ther 1981;218:653-661.

23. Weintraub WS, Hattori S, Agarwal JB, Bodenheimer MM, Banka VS, Helfant RH. The effects of nifedipine on myocardial blood flow and contraction during ischemia in the dog. Circulation 1982;65;49-53.

24. Nayler WG, Grau A, Slade A. A protective effect of verapamil on hypoxic heart muscles. Cardiovasc Res 1976;10;650-662.

25. Schaper W, J ewi P, Flameng W, Gijpen L. Myocardial steal provided by coronary artery occlusion. Basic Res Cardiol 1973;68:3-20.

26. Borgers M, Ver Donck L, Vanderplassche G. Pathophysiology of cardiomyocytes. Ann NY Acad Sci 1988;522:433-453.

27. Sperelakis $\mathrm{N}$. Regulation of calcium slow channels of cardiac muscle by cyclic nucleotides and phosphorylation. $J \mathrm{Mol}$ Cell Cardiol 1988;20:75-105.

28. Dhalla NS, Panagia V, Singal PK, Makino N, Dixon IMC, Dyolfson DA. Alterations in heart membrane calcium transport during the development of ischemia-reperfusion injury. J Mol Cell Cardiol 1988;20:3-13.

29. Ehlert FJ, Roeske WR, Itoga E, Yamamura HI. The binding of [3H]nitrendipine to receptors for calcium channel antagonists in the heart, ccrebral cortex and ileum of rats. Life Sci 1982;30:2191-2202.

30. Higgins AJ, Blackburn $\mathrm{KJ}$. Prevention of reperfusion damage in working rat hearts by calcium antagonists and calmodulin antagonists. $J$ Mol Cell Cardiol 1984;16:427-438.

31. Nayler WG, Panagiotopoulos S, Elz JS, Daly MJ. Calcium-mediated damage during postischaemic reperfusion. J Mol Cell Cardiol 1988;20:15-22.

32. Weglicki SB, Waite M, Stam AC. Association of phospholipase A with a myocardial membrane preparation containing the $\left(\mathrm{Na}^{++} \mathrm{K}^{+}\right)-\mathrm{Mg}^{2+}$-ATPase. $J$ Mol Cell Cardiol 1972;4:195-201.

33. Katz AM, Missinea FC. Lipid-membrane interactions and the pathogenesis of ischemic damage in the myocardium. Circ Res 1981;48:1-16.

34. Ferrari R, Ceconi $S$, Curello $C$, Guarnieri CM, Albertini A, Visiolo $O$. Oxygen-mediated myocardial damage during ischemia and reperfusion. Rise of the cellular defences against oxygen toxicity. $J$ Mol Cell Cardiol 1985;17:937945.

35. Korn NL, Pollack JV, Spath JA. Effects of intracoronary verapamil administration in a sheep model of acute myocardial ischemia and reperfusion. Circ Res 1988;62:1138-1146.
36. Irita K, Fujita I, Takeshiga K, Minakami S, Yoshitake J. Calcium channel antagonist induced inhibition of superoxide production in human neutrophils. Biochem Pharmacol 1986;35:20:3465-3471.

37. Jouvin-Marche E. Effect of the $\mathrm{Ca}^{2+}$ antagonist nifedipine on the release of platelet-activating factor (PAF-acether), slow-reacting substance, and $\beta$-glucuronidase from human neutrophils. Eur J Pharmacol 1983;89:19-26.

38. Hearse DJ. Reperfusion of ischemic myocardium. J Mol Cell Cardiol 1977;9:605-613.

39. Shen AC, Jenrings RB. Kinetics of calcium accumulation in acute myocardial ischemic injury. Am J Pathol 1972:67:235-243.

40. Rao PS, Cohen MV, Moeller HS. Production of free radical and lipid peroxidase in early experimental myocardial ischemia. (Rapid communication.) $J$ Mol Cell Cardiol 1983;15:713-716.

41. Camilleri JP, Joseph D, Amat D, Fabianai JN. Impaired sarcolemmal membrane permeability in reperfused ischemic myocardium. Virchows Arch 1980;388:68-76.

42. Asano $M$, Suzuki $Y$, Hidaka $H$. Effects of various calmodulin antagonists on contraction of rabbit aortic strips. J Pharmacol Exp Ther 1982;220:191-196.

43. Bourdillon PD, Poole-Wilson PA. The effects of verapamil, quiescence, and cardioplegia on calcium exchange and mechanical function in ischemic rabbit myocardium. Circ Res 1982;50:360-368.

44. Werns SW, Lucchesi BR. Free radicals and ischemic tissue injury. Trends Pharmacol Sci 1990;11:161-166.

45. Chi L, Tamura Y, Hoff PT, Macha M, Gallagher KP, Schork MA, Lucchesi BR. Effect of superoxide dismutase on myocardial infarct size in the canine heart after 6 hours of regional ischemia and reperfusion: a demonstration of myocardial salvage. Circ Res 1989;64:665-675.

46. Kuzuya T, Hoshida S, Kim Y, Nishida M, Fuji H, Kitabatake A, Tada M, Kamada $T$. Detection of oxygen-derived free radical generation in the canine postischemic heart during late phase of reperfusion. Circ Res 1990;66:1160-1165.

47. Lucchesi BR. Modulation of leukocyte-mediated myocardial reperfusion injury. Ann Rev Physiol 1990;52:561-576.

48. Kaneko M, Elimban V, Dhalla NS. Mechanism for depression of heart sarcolemmal $\mathrm{Ca}^{2+}$ pump by oxygen free radicals. Am J Physiol 1989;257:H804H811.

49. Kaneko M, Beamish RE, Dhalla NS. Depression of heart sarcolcmmal $\mathrm{Ca}^{2+}$ pump activity by oxygen free radicals. Am J Physiol 1989;256:H368-H374.

50. Bolli R, Jeroudi MO, Patel BS, Aruoma Ol, Halliwell B, Lai EK, McCay PB. Marked reduction of free radical generation and contractile dysfunction by antioxidant therapy begun at the time of reperfusion. Evidence that myocardial "stunning" is a manifestation of reperfusion injury. Circ Res 1989;65:607-622. 